\title{
Rede colaborativa de professores que ensinam Matemática: articulando ensino, pesquisa e extensão
}

\author{
Renata Prenstteter Gama ${ }^{1}$ \\ Bárbara C. M. Sicardi Nakayama ${ }^{2}$
}

\begin{abstract}
Resumo: O artigo objetiva analisar as articulações realizadas entre ensino, pesquisa e extensão no âmbito de um projeto que pertence ao Programa Observatório da Educação para evidenciar os tipos de práticas que potencializam o desenvolvimento profissional docente. Para isso, selecionaram-se: memórias das reuniões; narrativas dos professores e duas dissertações. A pesquisa qualitativa e interpretativa utilizou referenciais sobre as narrativas como movimento de investigação-formação, concepções de desenvolvimento profissional e parceria na formação de professores. Os resultados evidenciaram que os professores, ao participarem de formações, reflexões e sistematizações compartilhadas sobre suas próprias práticas, desenvolvem uma postura investigativa com a construção da autoria e autonomia emancipatória no exercício da profissão docente. Também há destaque para a fertilidade das narrativas como estratégia de reflexão, para a potencialidade da indissociabilidade entre ensino, pesquisa e extensão.
\end{abstract}

Palavras-chave: Observatório da Educação, desenvolvimento profissional, colaboração

\section{Network collaborative teacher teaching math: connection between education, research and extension}

\begin{abstract}
The target of this article is evaluate the connection between the teaching, research and university extension into one project that belongs to "Programa Observatório da Educação" to highlight the types of practices that enhance the professional development of teachers. Selected: Meeting memories; narratives of teachers and two master's thesis. The qualitative and interpretative research used references about the narratives as formation-research stool, career development ideas and partnership in teacher education. The results showed that the teachers to participate in training, shared reflection and systematization of their own practices develop an investigative approach to the construction of authorship and emancipatory autonomy in the exercise of the teaching profession. There is also emphasis on the fertility of the narratives as reflection strategy for the potential of inseparability teaching research and extension.
\end{abstract}

Keywords: Education Observatory, professional development, collaboration

1 Doutora em Educação: Educação Matemática pela UNICAMP em 2007. Professora do Programa de Pós-Graduação em Educação (PPGEd) da UFSCar-campus Sorocaba e do Programa de Pós-Graduação Profissional em Educação (PPGPE) da UFSCar-campus São Carlos. E-mail: renatapgama@gmail.com

2 Doutora em Educação: Educação Matemática pela UNICAMP em 2008. Professora do Programa de Pós-Graduação em Educação (PPGEd) da UFSCar-campus Sorocaba. E-mail: barbara.sicardi@gmail.com 


\section{Introdução}

Este artigo foi produzido no âmbito do projeto de pesquisa "Rede colaborativa de práticas na formação de professores que ensinam matemática: múltiplos olhares, diálogos e contextos", que pertence ao Programa Observatório da Educação na modalidade de rede. Este projeto está em andamento desde 2013, sediado na Universidade Federal de São Carlos - UFSCar e com dois núcleos (Universidade Federal do ABC - UFABC e Pontifícia Universidade Católica de São Paulo - PUCSP), tendo como objetivo geral compreender os múltiplos olhares e contextos trazidos pelos formadores, pelos professores em serviço (especialmente os iniciantes) e pelos licenciandos, enquanto dialogam e problematizam em rede a respeito das diferentes práticas docentes para melhorar o ensino de matemática, das práticas de inserção e sustentabilidade na docência e dos diferentes conhecimentos sobre, na e da prática no processo formativo (Cochran Smith \& Lytle, 1999).

Para este artigo foram analisadas as articulações realizadas entre ensino, pesquisa e extensão nos anos de 2013 e 2014, no âmbito do OBEDUC-UFSCar-Campus Sorocaba, para evidenciar os tipos de práticas que potencializam o desenvolvimento profissional docente. A estrutura do texto que segue contempla primeiramente os referenciais teóricos da área de formação de professores que fundamentam o estudo, em especial sobre as narrativas de formação como movimento de investigação-formação, modelos e concepções de desenvolvimento profissional e parceria na formação de professores. Em seguida apresentamos três espaços que ilustram as dimensões do ensino, da pesquisa e da extensão e que integram as ações do OBEDUC na UFSCar. E, por último, são evidenciadas as articulações dos espaços formativos.

\section{Aspectos teóricos e metodológicos}

As produções do projeto investigado têm como pressuposto o entendimento de que o desenvolvimento profissional se potencializa com práticas formativas que se estruturam e se organizam a partir do estabelecimento de parcerias com características colaborativas e da escrita reflexiva, objetivada e partilhada dos professores sobre os processos educativos em que estão envolvidos, que vivenciam e conduzem.

Nas pesquisas na área de educação, adota-se a história de vida - mais especificamente, o método (auto) biográfico e as narrativas de formação - como movimento de investigação-formação, seja na formação inicial ou continuada de professores, seja em pesquisas centradas nas memórias e (auto)biografias de professores.

A narrativa (auto)biográfica pertence a um processo de transformação que o indivíduo exerce, pela linguagem, sobre seu vivido e pelo qual ele tende a constituir 
sua identidade e sua relação com o mundo. É um processo de construção identitária elaborado pela palavra e que permite "colocar uma ordem narrativa" em sua própria vida, ao "contar sobre (si mesmo) uma história compreensível e, sobretudo, aceitável” (Ricoeur, 1997, p. 25).

Trabalhar com narrativas na pesquisa e/ou no ensino é partir para a desconstrução/construção das próprias experiências, tanto do professor/pesquisador como do sujeito da pesquisa. Exige que a relação dialógica se instale, criando uma cumplicidade de dupla descoberta.

Outro aspecto importante a considerar, destacado por Sicardi (2008), diz respeito ao fato de que o trabalho com as narrativas é profundamente formativo. A esse respeito, a autora afirma que

esta compreensão, provavelmente, é que tem feito a pesquisa qualitativa tornar-se, mesmo sem a intenção precípua de fazer uma intervenção, em uma alternativa de formação. Ao mesmo tempo que o sujeito organiza suas idéias para o relato - quer escrito, quer oral - ele reconstrói sua experiência de forma reflexiva e, portanto, acaba fazendo uma auto-análise que lhe cria novas bases de compreensão de sua própria prática. (p.77)

A perspectiva de trabalhar com as narrativas tem o propósito de fazer a pessoa tornar-se visível para ela mesma. Trata-se de um diálogo sobre suas vivências, estabelecido entre a prática vivida e as construções teóricas nela formuladas. É a ideia de reflexão-ação, tão bem explicitada por Nóvoa (1995), que pode tornar-se um dos melhores instrumentos de aprendizagem. O discurso construído sobre esse diálogo é que torna possível transformá-lo numa situação profundamente pedagógica.

A opção feita pela utilização das narrativas aponta, portanto, para o processo de desenvolvimento profissional docente. Esse processo possui uma diversidade de concepções - associadas à formação docente - que, em grande parte, destacam a aquisição de conhecimentos e habilidades relativos ao conteúdo ou à disciplina a ensinar. Porém, consideramos o desenvolvimento profissional de forma mais ampla, como Oliveira-Formosinho (2002) define:

Desenvolvimento profissional é uma caminhada que decorre ao longo de todo o ciclo de vida e envolve crescer, ser, sentir, agir .... Essa perspectiva de aprendizagem ao longo da vida leva-nos a conceituar o desenvolvimento profissional como uma caminhada que tem fases, que tem ciclos, que não pode ser linear, que se articula com os diferentes contextos sistêmicos que a educadora vai vivenciando. (p. 42) 
Entendemos o desenvolvimento profissional e seus elementos como

um processo pessoal e coletivo, interativo, dinâmico, contínuo, evolutivo e sem fim, que envolve aspectos conceituais e comportamentais. As aprendizagens advindas desse processo são de natureza pessoal, profissional, institucional, social e acontecem ao longo da trajetória de vida de cada um. Além disso, o desenvolvimento profissional dos professores depende também das políticas e dos contextos escolares nos quais realizam a sua atividade docente (Gama, 2007, p.29).

Cochran Smith e Lytle (1999), em relação às aprendizagens do professor para a formação profissional docente, analisam três concepções: "para, na e da" prática. A concepção de conhecimento "para" a prática é associada a iniciativas de formação continuada - as mais conhecidas e utilizadas - , englobando escolas e sistemas escolares inteiros. As aprendizagens são baseadas em teorias gerais e em descobertas de pesquisa, as quais os professores são treinados para implantar.

O conhecimento "na" prática fundamenta-se na ideia de que o conhecimento se origina na reflexão e na investigação da prática; a ênfase está no conhecimento em ação, nas reflexões do professor sobre a prática, nas investigações e nas narrativas sobre ela. Essas iniciativas estão centradas na ajuda aos professores, explorando problemas da prática que não podem ser resolvidos pela aplicação de teorias estabelecidas ou pela reconsideração de suas próprias suposições e raciocínios. Nos programas, os facilitadores trabalham, muitas vezes, com grupos de professores, que funcionam como equipe externa de apoio, levando os outros a questionar suas próprias suposições e reconsiderar as bases de suas ações e de suas crenças.

Da perspectiva do conhecimento "da" prática, os pesquisadores sugerem, para favorecer o desenvolvimento profissional, oportunidades para que os professores explorem e questionem suas (e dos outros) ideologias, suas interpretações e suas práticas. Isso significa que os professores aprendem ao desafiar suas próprias suposições; ao identificar questões importantes da prática; ao propor problemas; ao estudar seus próprios estudantes, salas de aula e escolas; ao construir e reconstruir o currículo; e ao assumir papéis de liderança e de protagonistas na busca da transformação das salas de aula, das escolas e das sociedades.

Podemos perceber que Cochran Smith e Lytle (1999), tanto na segunda perspectiva, de aprendizagem "na", como na terceira, "da" prática, destacam a importância da reflexão dos professores sobre suas práticas. Mas, sobretudo na terceira concepção, apontam para a relevância da pesquisa do professor em comunidades investigativas locais e de uma relação dialética teoria-prática, que acena para a importância de professores constituírem grupos de estudo e adotarem uma postura investigativa e questionadora de suas práticas. 
Na mesma direção, Foerste (2005) nos propõe o conceito de parceria colaborativa no âmbito da formação de professores, que, no seu entendimento, "cria condições para serem estabelecidas negociações concretas que identificam objetivos comuns e respeitam interesses específicos de cada instituição, considerando basicamente a universidade e a escola” (p. 117).

É nessa perspectiva que temos proposto estruturar o trabalho que vem sendo realizado no contexto do OBEDUC, e as duas dissertações selecionadas para este estudo buscaram o oferecimento de uma formação na qual houve a preocupação de constituir parcerias, priorizando o compartilhar conhecimentos e práticas pedagógicas de matemática entre professores universitários, professores da escola básica e licenciandos.

Neste trabalho selecionamos três espaços formativos e de investigação do projeto OBEDUC que representam as dimensões da pesquisa, do ensino e da extensão, respectivamente: o Grupo de Estudos e Pesquisa sobre Práticas Formativas e Educativas em Matemática (GEPRAEM), a disciplina de Metodologia e Prática de Ensino de Matemática oferecida ao curso de Pedagogia e a Atividade de Extensão intitulada "Etnomatemática na Educação Infantil: reflexões teóricas e metodológicas na formação e atuação de professores”, ofertada a professores da Educação Infantil da rede municipal de Sorocaba.

Assim, para este estudo selecionamos e analisamos as memórias das reuniões realizadas e as narrativas dos participantes do GEPRAEM e duas dissertações concluídas no âmbito do OBEDUC, que tiveram como objetivo estudar aspectos relativos à formação inicial (Graupner, 2013) e continuada (Romão, 2015) de professores e que tomam como objeto, respectivamente, os espaços de ensino e de extensão.

O GEPRAEM (CNPq) desenvolve o projeto OBEDUC em rede, que prevê, em uma das suas ações, a constituição de um grupo de estudos e pesquisas em cada um de seus núcleos. No caso da UFSCar, as atividades ocorrem quinzenalmente e congregam docentes universitários, pós-graduandos, docentes da escola básica e licenciandos de Matemática e de Pedagogia.

O projeto OBEDUC no grupo iniciou suas atividades em 2013, com a análise dos relatórios de avaliações externas elegidos e disponibilizados pelos próprios participantes. Desse trabalho resultou um mapeamento sobre os conhecimentos matemáticos que apresentavam as principais facilidades e dificuldades de domínio conceitual e metodológico na Educação Básica. Ele também deflagrou a escolha de temas de interesse para os estudos teóricos, os relatos de experiências e as pesquisas desenvolvidas no projeto.

Além dessa atividade, foram escritas e compartilhadas no coletivo as narrativas sobre as trajetórias escolares dos participantes com a matemática, intituladas "Eu e 
a matemática” (N1), em 2013, e a narrativa sobre as atividades vivenciadas no grupo de pesquisa, "Eu e o GEPRAEM" (N2) em 2014. Para este estudo, foram selecionadas as narrativas de três professoras da escola básica (identificadas pelas iniciais T, H, J), que participaram das reuniões do GEPRAEM, assim como das atividades nos outros dois espaços formativos de ensino e extensão mencionados.

A disciplina Metodologia e Prática do Ensino de Matemática, objeto de estudo da dissertação de Graupner (2013), vinculada ao OBEDUC, é regularmente oferecida ao curso de Pedagogia da UFSCar-Sorocaba. É coordenada por uma professora efetiva do Departamento de Ciências Humanas e Educação, que a propõe desde o início planejada em regime de colaboração. Gaupner foi convidada a participar do planejamento e, pelo mesmo princípio de colaboração, outros profissionais foram chamados para compor a equipe de trabalho. Com essa perspectiva, passaram a integrar o grupo uma professora da Educação Infantil (EI) da rede municipal de Araçoiaba da Serra, duas professoras - uma do $1^{\circ}$ e outra do $2^{\circ}$ ano - atuantes nos Anos Iniciais do Ensino Fundamental (AIEF), vinculadas à rede municipal de Sorocaba, dois professores do Ensino Fundamental (EF) II, um deles também doutorando e professor universitário. As professoras da EI e dos AIEF integram também o GEPRAEM.

A disciplina constituiu-se por 15 encontros semanais de 4 horas, totalizando 60 horas. As modalidades das ações desenvolvidas na totalidade dos encontros da turma abrangeram dimensões pedagógica, organizacional, profissional e social relacionadas ao ensino da matemática, pois envolveram aspectos do currículo, práticas pedagógicas, conduta dos alunos, formação continuada, condições de exercício profissional e cidadania, entre outros.

As aulas desenvolveram-se com a perspectiva de tratar interativamente com os alunos, os professores colaboradores e os estagiários sobre as tendências do Ensino da Matemática como eixo para a compreensão dos conteúdos conceituais, atitudinais e procedimentais no ensino e na aprendizagem da EI e dos AIEF. Nessa perspectiva, a disciplina se estruturou, visando abordar questões relevantes do ensino, especialmente aquelas relativas ao conhecimento matemático e a seu papel na EI e nos AIEF; aquelas atinentes à definição do conteúdo do ensino de matemática, aos saberes e conhecimentos a serem introduzidos no ensino regular - conforme RCNEI e PCN de matemática -, em termos desejáveis que os alunos aprendam; e, por fim, as que tratam do desenvolvimento de processos alternativos de ensino e de aprendizagem na perspectiva da construção ativa do conhecimento matemático pelo aluno.

A pesquisa de Graupner (2013) objetivou identificar quais as contribuições da disciplina Metodologia e Prática do Ensino da Matemática para a formação dos 
professores que ensinam matemática nos AIEF, e, com o objetivo de mostrar o processo vivenciado durante a disciplina, foram selecionados para análise, dentre as produções dos alunos, os relatos de suas trajetórias escolares, os cartazes produzidos sobre "como não deve ser o ensino da matemática" e o trabalho final da disciplina, incluindo as representações (imagens) de "memórias do futuro".

A atividade de extensão configurou-se como um curso de formação continuada para professores da Educação Infantil da rede pública municipal de Sorocaba, no qual também foi desenvolvida uma dissertação. O curso foi oferecido pelo Departamento de Metodologia de Ensino (DME) da UFSCar, no primeiro semestre de 2014, e teve como objetivo constituir um grupo de estudos sobre a Etnomatemática na Educação Infantil e problematizar práticas escolares nesse nível de ensino.

Inicialmente, foram inscritos 25 professores da Rede Municipal de Ensino de Sorocaba, por meio de formulário encaminhado às Instituições de Educação Infantil e escolares. Após o segundo encontro, o grupo contou com 13 professoras que participaram da formação e da pesquisa de mestrado no período de março a junho de 2014.

O curso de formação continuada teve a duração 60 horas, sendo a carga horária distribuída em 36 horas presenciais e 25 horas de encontros a distância, que, mediados pelo ambiente virtual de aprendizagem (moodle), oportunizaram a elaboração de narrativas orais e escritas, a socialização de experiências vividas, questionamentos e reflexões sobre práticas uniformizadas no ensino de matemática.

Para a pesquisa, Romão (2015) teve como objetivo geral compreender o processo de formação continuada, em diálogo com a Etnomatemática, em um grupo de professoras que lecionam na Educação Infantil, e optou por selecionar dentre todas as atividades desenvolvidas no processo de formação continuada três instrumentos para análise: 1. Narrativas orais audiogravadas das professoras nas reuniões do grupo sobre a produção e a (res)significação de uma proposta de atividade para a Educação Infantil. 2. Narrativas escritas pelas professoras participantes sobre o desenvolvimento da atividade na Educação Infantil. 3. Questionário inicial e final respondidos pelas participantes.

Assim, a seguir apresentamos um estudo metanalítico que permite uma “análise crítica de um conjunto de estudos já realizados, tentando extrair deles informações adicionais que permitam produzir novos resultados, transcendendo aqueles anteriormente obtidos" (Fiorentini \& Lorenzato, 2006, p. 71). Nessa perspectiva, este estudo tem como objetivo compreender as articulações entre ensino, pesquisa e extensão, ocorridas em três espaços de investigação descritos a seguir, e evidenciar os tipos de práticas que potencializam o desenvolvimento profissional docente. 


\section{As articulações dos espaços formativos com a pesquisa na formação de professores que ensinam matemática}

Para o estudo metanalítico dos dados foram constituídas duas categorias: a primeira busca evidenciar as práticas formativas nos diferentes espaços de ensino, pesquisa e extensão; e a segunda vislumbra identificar indícios de desenvolvimento profissional dos participantes nesses contextos.

\subsection{Práticas formativas nos diferentes espaços do OBEDUC}

O projeto do OBEDUC prevê práticas formativas nas diferentes atividades desenvolvidas com o pressuposto das características de parceria e de colaboração entre a universidade e a escola. Os diferentes espaços do OBEDUC, reiteramos, serão aqui representados pelo GEPRAEM, pelo contexto da disciplina Metodologia e Prática do Ensino de Matemática ofertada ao curso de Pedagogia e pelo curso de extensão ofertado a professoras da Educação Infantil.

Ao selecionarmos o material de análise, podemos perceber que as principais práticas desenvolvidas no GEPRAEM, as narrativas sobre o "eu e a matemática", trouxeram ao grupo a problematização das práticas escolares vivenciadas enquanto alunos da escola básica, um olhar sobre a sua formação profissional e também a percepção de suas influências para o ensino de matemática. Podemos visualizar a relevância dessa prática para novas ressignificações a partir de trechos da narrativa da professora J:

aprendi a ler e a fazer "continhas" do tipo "arme e efetue". Até a quarta série foi desse modo, só ia aumentando o valor posicional dos números....

O tempo passou, na faculdade de Pedagogia, eu acreditava que não haveria a disciplina de Matemática, mas havia, então, tive de aprender. No entanto, aprendi de um jeito que já esqueci, pois comecei a lecionar na Educação Infantil, já que não há uma exigência em relação ao ensino e aprendizagem da matemática em sua totalidade, fui para o lado da alfabetização, no qual estudei com afinco....

Depois de seis anos, sendo ouvinte de um grupo de pesquisa, me deparei refletindo demais sobre a minha prática e pude perceber o quanto estava equivocada na maneira como lecionava, os meus alunos de quatro anos não sabiam contar, dividir, resolver situações problemas, ou seja, não sabiam nada de Matemática. Mudei completamente o meu cronograma escolar e incluí projetos que pudessem desenvolver essas habilidades nos alunos, de maneira lúdica e participativa, pois não queria que eles fossem reféns do meu mau aprendizado no passado. Minhas aulas ganharam mais envolvimento e compreensão dos alunos. (J, N1) 
Essa prática de problematização das nossas próprias trajetórias, ao utilizar a narrativa como instrumento de formação, trouxe uma articulação dos diversos tempos sobre o ensino de matemática e um engajamento inicial dos participantes.

Ainda em relação às narrativas, a seguir citamos dois excertos que evidenciam a percepção das professoras sobre as dinâmicas e sobre suas próprias aprendizagens, ao participar do grupo de pesquisa, e a articulação que ocorre entre ensino, formação e prática pedagógica.

Estar no grupo GEPRAEM é uma grande oportunidade, estou aprendendo muito e, como professora, sinto a necessidade desse aprendizado, pois, a cada encontro com o grupo, sinto uma inquietação em aprender mais. (J, N1)

No início de 2013 surgiu a oportunidade de participar do GEPRAEM no qual fizemos a inscrição e participamos da entrevista coordenada pelas prof ${ }^{\mathrm{a} s}$ e após todo o processo, iniciamos nossos encontros. Encontros estes que foram se tornando cada vez mais enriquecedores, as reflexões críticas e as socializações de experiências compartilhadas no grupo, o mapeamento, a discussão e as análises tanto individuais ou coletivas de temáticas veio nos oferecer uma nova e mais abrangente visão sobre o ensino da matemática, a formação dos docentes e a prática pedagógica. ( $\mathrm{H}, \mathrm{N} 2)$

Outra prática formativa destacada pelas professoras na segunda narrativa aponta o envolvimento dos participantes com o processo de produção de conhecimento na área de Educação Matemática:

E mais experiências ocorreram durante o ano, a participação na arguição dos projetos de pesquisas realizados por nossos companheiros do grupo, no qual aprendemos muito. (H, N2)

Durante o decorrer deste ano quanta aprendizagem, experiências novas vividas e adquiridas levando ao crescimento pessoal e profissional. Mês de junho um novo desafio, a participação no GEPRAEM nos oportunizou a apresentação do relato de experiência no IV SHIAM (IV Seminário Nacional de Histórias e Investigações de/em Aulas de Matemática) na UNICAMP com texto aprovado e publicado para meu orgulho e da minha companheira de relato a $\mathrm{T}$. $(\mathrm{H}, \mathrm{N} 2)$

$\mathrm{O}$ ano foi muito produtivo também, quando pudemos participar das qualificações para o mestrado de companheiros que nos ajudam a ter novas inspirações para, quem sabe num futuro, também nós nos aventuremos nessa empreitada. (T, N2)

A professora H aponta a dinâmica e as aprendizagens profissionais quando são estabelecidos arguidores para a problematização e a análise de projetos de pesquisa que estão em andamento no grupo e reconhece a sua oportunidade de sistematizar, 
refletir e divulgar a sua prática, com a colaboração do grupo, em uma articulação do ensino e dos procedimentos de pesquisa.

Essa articulação também é apontada por J, quando descreve em sua narrativa os eventos de que participou e suas contribuições:

Participei, também, de eventos relacionados à Educação Matemática, o primeiro foi em maio, o Encontro Paulista de Educação Matemática (EPEM), apresentei um plano de aula, realizado com as crianças para as quais lecionei, sobre jogos e brincadeiras na Educação Infantil que envolve conceitos matemáticos. $O$ público que assistiu era constituído de pesquisadores e doutores na área de matemática e ficaram interessados com o tema, pois não imaginavam o quanto as crianças pequenas podem aprender em relação aos conceitos matemáticos. $\mathrm{O}$ segundo encontro foi realizado no Observatório da Educação junto com os grupos dos três polos, expus o pôster sobre Colaboração do OBEDUC para os anos iniciais e Educação Infantil, no qual eu, a H e a $\mathrm{T}$ (integrantes do GEPRAEM), relatamos um pouco sobre o quanto a nossa participação no grupo refletiu em sala de aula, algumas pessoas que leram acharam bem interessante e destacaram as habilidades necessárias que a criança precisa ter para aprender Matemática nos anos finais do Ensino Fundamental. O último evento foi o 4o Fórum de Práticas de Gestão organizado pelo Sistema Apostilado Positivo que é utilizado no munícipio em que trabalho. Apresentei um relato de experiência sobre como utilizo a Matemática na Educação Infantil, frisei bastante a importância da minha participação no GEPRAEM, pois foi através dela que consegui modificar minha prática em sala de aula. As pessoas que ouviram o relato ficaram intrigadas, pois também davam aulas na Educação Infantil e nunca haviam organizado planos de aula contemplando conceitos matemáticos e que com minha apresentação perceberam que é possível trabalhá-los de forma prazerosa e envolvente. (J, N2)

Na escrita de J, fica claro que o grupo fortalece o refletir sobre sua prática pedagógica e o repensar da matemática na Educação Infantil. Também se evidencia a rede ampliada que a participação do grupo em diversos eventos pode proporcionar.

As narrativas ainda revelam a ideia de Nóvoa (1995) da reflexão-ação como instrumento e nos apresentam indicativos de aprendizagem profissional na perspectiva do conceito de desenvolvimento profissional (Gama, 2007), ao mencionar as práticas formativas vivenciadas, tal como se pode observar a seguir:

Minhas relações com ela [Matemática] se estreitaram.... E agora ela faz parte da minha vida, muitas horas por dia! Pesquisa, educação matemática, matemática, grupos de estudo... formação profissional. Uma certeza eu tenho... Eu quero mais... (Graupner, N1) 
Depois de ter participado de um curso de extensão, onde éramos um grupo que discutia possibilidades do ensino de matemática nos anos iniciais, e de participar como colaboradora nas aulas de Metodologia de Matemática para turmas de Pedagogia da UFSCar, iniciei no ano de 2013 minha participação no OBEDUC/GEPRAEM como bolsista da CAPES.... Finalizando o ano com chave de ouro, assistir a defesa de mestrado da Graupner foi um momento de grande emoção, que eu nunca havia presenciado. (T, N2)

O projeto OBEDUC em desenvolvimento prevê, como uma de suas ações, a extensão universitária a partir de conhecimentos construídos no grupo de pesquisa. Ao analisar a formação continuada oferecida pela mestranda Romão (2015) para professores da Educação Infantil da rede municipal de Sorocaba, podemos evidenciar as contribuições do GEPRAEM em suas práticas e dinâmicas.

A dissertação apresenta o cronograma detalhado da formação (Romão, 2015, p.120), em que traz evidências de que a narrativa foi utilizada como instrumento formativo e integrador do grupo, como vimos no GEPRAEM. Também outras práticas, como o estudo teórico-metodológico sobre o ensino de matemática e o olhar sistematizado sobre a própria prática pedagógica, compuseram a concepção voltada ao desenvolvimento profissional dos participantes.

Algumas dessas evidências são descritas no próprio cronograma, a partir da demanda para os professores em relação às atividades desenvolvidas na formação continuada:

- Selecionar atividades de matemática que costuma oferecer na Educação infantil (elaborar um anexo com título, faixa etária, noções matemáticas envolvidas e os materiais utilizados) [Atividade 1]

- Sugestão de temas para os encontros [Atividade 3]

- Após a leitura do texto de Monteiro, quais as considerações e os questionamentos que poderemos levantar, tendo também, nossa própria experiência docente como suporte teórico? [Atividade 6]

- Atividade de (res) significação realizada em grupo no encontro anterior e sua aplicação junto às crianças; [Atividade 7]

- Gravar uma aula de matemática com os alunos com a temática "Brincadeiras infantis nas aulas de matemática" [atividade 8]

- Socialização do vídeo - gravação da vivência oferecida às crianças com a temática "Brincadeiras infantis nas aulas de matemática" [atividade 9]

- Proposta: Escrever um artigo sobre a participação no curso de extensão [ambiente virtual] 
Podemos perceber o movimento das práticas de formação pela atividade que os professores socializaram como exemplo de suas práticas pedagógicas com seus alunos da Educação Infantil: escolheram uma atividade para reconstruir, aplicar, registrar e (res)significar conhecimentos da docência; e, por último, sistematizaram e escreveram sobre o processo vivido.

Esse movimento realizado na prática de formação vai ao encontro dos conhecimentos "da" prática na perspectiva de Cochram Smith e Lytle (1999), a qual prioriza a colaboração e o compartilhar de dinâmicas e atividades pedagógicas. Esses conhecimentos articulam o movimento de estudo, pesquisa e ensino com as crianças da Educação Infantil. A professora J declara que

o terceiro evento [de que participou] foi o II Encontro de Educação Matemática nos Anos Iniciais, que apresentei, junto com a $\mathrm{H}$ e a T, o relato de experiência sobre o curso de extensão e incluímos na apresentação também a colaboração do grupo GEPRAEM para a nossa profissão [acréscimos nossos]. (J, N2)

Esse excerto da narrativa de J, membro do GEPRAEM que também participou da formação continuada, evidencia a articulação do grupo de pesquisa com a extensão universitária e o processo de refletir juntos. A esse respeito, Romão (2015) afirma que

as práticas desenvolvidas no curso de extensão apontam para um compartilhar de ideias que favoreceram essa reflexão no grupo e pelo grupo, desencadeando um (res) significar de concepções e de práticas que implicam em viver uma forma diferente de fazer Matemática, de aprender e de ensinar. (p.106)

Pelo que foi exposto, podemos afirmar que a narrativa provoca mudanças tanto nos sujeitos da investigação quanto nas mestrandas-pesquisadoras. Tomando distância do momento de sua produção, é possível, ao "ouvir" a si mesmo ou ao "ler" seu registro, que o produtor da narrativa seja capaz, inclusive, de ir teorizando a própria experiência. Esse pode ser um processo profundamente emancipatório, em que o sujeito aprende a produzir sua própria formação. Essa possibilidade requer algumas condições: é preciso que o sujeito esteja disposto a analisar criticamente a si mesmo, a separar olhares enviesadamente afetivos presentes na caminhada, a pôr em dúvida as crenças e os preconceitos - enfim, a retomar seu processo histórico para melhor compreendê-lo e atribuir a ele novo sentido.

A maneira como o professor conduz a sua prática é consequência de inúmeras referências, entre elas suas histórias familiares, seus percursos escolares e acadêmicos, sua convivência com o ambiente de trabalho, sua inserção cultural no tempo e 
no espaço. Provocá-lo a organizar narrativas dessas referências é fazê-lo viver um processo profundamente pedagógico, em que sua condição existencial é o ponto de partida para a construção de seu desempenho na vida e na profissão. Através da narrativa, ele vai descobrindo os significados que tem atribuído aos fatos que viveu e, desse modo, vai reconstruindo a compreensão que tem de si mesmo.

Assim, vai se reforçando a ideia de que essas reflexões favorecem a percepção de que a produção de narrativas serve, ao mesmo tempo, como procedimento de pesquisa e como alternativa de formação. Ela permite desvendar informações quase misteriosas postas na narração pelo sujeito que, muitas vezes, nunca havia sido estimulado a expressar organizadamente seus pensamentos.

Para além das questões relacionadas às narrativas, destacamos ainda a potencialidade da indissociabilidade entre ensino, pesquisa e extensão, prevista no projeto OBEDUC como proposta formativa e de produção de conhecimento, assim como o reconhecimento do lugar da universidade na produção de conhecimento e na organização de espaços de formação continuada.

\subsection{Desenvolvimento Profissional dos participantes do OBEDUC}

Na seção anterior apontamos articulações nas práticas de formação e de pesquisa vivenciadas pelos participantes do GEPRAEM. A partir dessas articulações, analisaremos momentos em que as mestrandas e as professoras envolvidas nos três espaços de formação apontam indícios de desenvolvimento profissional.

As duas mestrandas pertencentes a esse OBEDUC trouxeram reflexões sobre o seu processo vivido:

Nesse momento, é importante considerar as implicações da pesquisa na própria prática educativa da pesquisadora e da professora. Pois as reflexões e as negociações desenvolvidas nos encontros no curso de extensão, permitiram uma auto-reflexão pelas leituras, discussões coletivas e pelas próprias intervenções realizadas sobre as concepções, crenças e saberes das professoras. (Romão, 2015, p.107)

Posso afirmar que minha participação na disciplina Metodologia e Prática do Ensino da Matemática foi muito válida, pois apesar de não ter tido contato anterior com alunos de graduação, pude "trocar" tanto com a professora da disciplina e demais colaboradores quanto com os estudantes, um pouco de minha experiência enquanto professora da Educação Básica e formadora de professores, o que me fez refletir sobre os limites, possibilidades e o importante papel do formador para a formação inicial de professores para o ensino de matemática nos AIEF. (Graupner, 2013, p.79) 
Esses excertos caracterizam, nos espaços da disciplina e/ou da extensão universitária, um movimento de formação “da” prática (Cochran Smith \& Lytle, 1999). Importa ainda destacar a reflexão de Romão (2015), indicando as articulações no processo de pesquisa em relação à formação inicial e continuada de professores:

O trabalho está focado na formação continuada, mas aponta também para um repensar da formação inicial dos professores da Educação Infantil na perspectiva do trabalho com a Matemática oferecendo espaços de discussão e reflexão crítica sobre as próprias crenças e saberes docentes enquanto trajetória, no intuito de (res) significá-los de modo a valorizar as culturas infantis e os muitos modos de se fazer Matemática. (p. 108)

Por outro lado, sobressaem as percepções e as reflexões das professoras sobre o seu próprio processo de desenvolvimento profissional em relação a novas práticas pedagógicas, a novas concepções sobre o ensino e a aprendizagem de matemática, em especial na Educação Infantil.

No âmbito profissional já no início do ano participei de um curso de extensão ministrado pela mestranda e por sua orientadora (também integrantes do GEPRAEM), que me permitiu aprender o "conceito" de que a criança é capaz de pensar "matematicamente", mas isso depende da situação que é apresentada a ela, pois muitas vezes, esperamos respostas prontas delas, esse fato era muito presente em minha sala de aula. (J, N2)

Meu planejamento pedagógico após o curso de extensão começou a ser elaborado respeitando os saberes das crianças, eram feitas propostas que as confrontassem para estimulá-las a pensar.... Percebi que elas ficaram muito mais envolvidas e que o diálogo foi primordial, pois ao tentarem resolver uma situação problema, elas conversavam bastante, davam opiniões, realizavam estimativas de respostas e muitas vezes para a realização de uma situação-problema era necessário disponibilizar um dia inteiro de aula para que conseguissem chegar à finalidade da proposta. (J, N2)

Nos excertos, os relatos indicam os aprendizados e as mudanças na prática pedagógica da professora, considerando uma nova forma de planejar situações de ensino e desenvolvimento das atividades, a partir da valorização do pensar e dialogar das crianças. Por outro lado, também valorizam as situações voltadas ao processo de sistematizações relacionado a práticas investigativas:

Percebi que houve um crescimento significativo em minha formação pedagógica. O grupo proporcionou um crescimento significativo em 
minha formação pedagógica através de estudos e a prática de pesquisa e de redação de textos relacionados à minha prática em sala de aula. Fizemos análises dos trabalhos dos colegas de grupo e produção de um trabalho junto com a $\mathrm{H}$, para apresentarmos no SHIAM, senti minha prática mais valorizada. Percebi que se continuasse no caminho apenas "dar aulas", sem participar do OBEDUC, correria o risco de perder o prazer pela educação e consequentemente, minha inspiração na profissão. Durante o decorrer do ano pudemos participar das qualificações para o mestrado de companheiros do grupo de pesquisa que nos inspirou e nos encorajou a aventurarmos a dar início a nosso projeto de pesquisa. Sinto o nosso grupo mais fortalecido e o apoio que cada um dá para o outro nos permite persistir em nossa caminhada. $(\mathrm{H}, \mathrm{N} 2)$

As práticas investigativas citadas - os estudos, a pesquisa sobre suas próprias práticas e a participação em eventos científicos - valorizaram o seu trabalho e evidenciam o processo de desenvolvimento profissional que integrou a vivência de práticas formativas nos diferentes espaços de ensino, pesquisa e extensão potencializado pela parceria colaborativa (Foerste, 2013) entre unversidade e escola.

\section{Considerações Finais}

Ao buscarmos analisar as articulações realizadas entre ensino, pesquisa e extensão no âmbito do projeto OBEDUC, pudemos identificar que as práticas do GEPRAEM priorizaram o estudo teórico, a percepção da trajetória dos participantes, a construção e a problematização coletiva de projetos de pesquisa e relatos de experiência.

Essas práticas têm potencializado o desenvolvimento profissional dos professores, ao realizarem reflexões e sistematizações compartilhadas sobre suas próprias práticas, promovendo uma postura investigativa, com a construção da autoria e da autonomia emancipatória no exercício da profissão docente.

Os resultados desta pesquisa também apontam para a fertilidade das narrativas como estratégia de reflexão; para a indissociabilidade entre ensino, pesquisa e extensão prevista no projeto OBEDUC como proposta formativa e de produção de conhecimento; e para o entendimento de que a ideia de rede não se pauta pelo princípio da padronização, mas, sobretudo, considera a subjetividade e a especificidade dos diferentes contextos, fortalecendo o conceito de colaboração nos grupos de pesquisa.

$\mathrm{O}$ que se apresenta neste trabalho é reflexo do percurso que temos vivido como pesquisadoras-formadoras de professores-pesquisadores. A maneira singular como os textos estão estruturados e a organização das narrativas são desencadeadas por esse conjunto complexo de relações que nos constitui como sujeitos-autoras deste trabalho. 


\section{Referências}

Cochran-Smith, M., \& Lytle, S. (1999). Relationships of knowledge and practice: Teacher learning in communities. In A. Iran-Nejad, \& C. D. Pearson (Eds.), Review of Research in Education, 24, 251-307.

Fiorentini, D., \& Lorenzato, S. (2006). Investigação em educação matemática: percursos teóricos e metodológicos. Campinas, SP: Autores Associados.

Foerste, E. (2005). Parceria na formação de professores. São Paulo: Cortez.

Gama, R. P. (2007) Desenvolvimento profissional com apoio de grupos colaborativos:o caso de professores de Matemática em início de carreira. Tese de Doutorado em Educação: Educação Matemática, Universidade Estadual de Campinas, Campinas. Retirado em 02 de março de 2015, de http://www.bibliotecadigital.unicamp.br/document/?code=vtls000423425

Graupner, M. (2013). Contribuição das práticas educativas para o ensino da matemática nos anos iniciais: análise de uma experiência disciplinar colaborativa. Dissertação de Mestrado em Educação, Universidade Federal de São Carlos, Sorocaba. Retirado em 02 de março de 2015, de http://www.ppged.ufscar.br/mce/arquivo/pagina35/graupner,_marli_de_carvalho_-_contribui\%C3\%A7\%C3\%A3o_das_pr\%C3\%A1ticas_educativas_para_o_ensino_da_matem\%C3\%Altica_....pdf

Nóvoa, A. (Org.) (1995). Os professores e sua formação. Lisboa: Dom Quixote.

Oliveira-Formozinho, J. (2002). O desenvolvimento profissional das educadoras de infância: entre os saberes e os afetos, entre a sala e o mundo. In J. Oliveira-Formozinho, \& T. M. Kishimoto (Orgs.), Formação em contexto: uma estratégia de interação. São Paulo: Pioneira Thompson Learning.

Ricoeur, P. (1997). Tempo e narrativa. Campinas, SP: Papirus.

Romão, P. (2015). (Res) significação dos saberes docentes para educação infantil, a partir do diálogo com a etnomatemática. Dissertação de Mestrado em Educação, Universidade Federal de São Carlos, Sorocaba. Retirado em 02 de março de 2015, de http://www.ppged. ufscar.br/index.php

Sicardi, B. C. M. (2008) Biografias educativas e o processo de constituição profissional de formadores de professores de matemática. Tese de Doutorado em Educação: Educação Matemática, Universidade Estadual de Campinas, Campinas. Retirado em 02 de março de 2015, de http://www.bibliotecadigital.unicamp.br/document/?code=vtls000440035

Submetido em: $26 / 01 / 2016$

Aceito em: 01/03/2016 